\title{
Simulation of Spatio-temporal Variations of Methylmercury in Aha Reservoir, Guizhou, China by WASP
}

\author{
Ying Liu, Xiangliang Pan, Anming Bao \\ Xinjiang Institute of Ecology and Geography, Chinese Academy of Sciences, Urumqi, 830011, China
}

\begin{abstract}
Two-dimensional, 8-segment mercury module of Aha Reservoir (surface area $4.15 \mathrm{~km}^{2}$; volume $0.445 \times 109 \mathrm{~m}^{3}$ ) was developed using the WASP 7 modeling system. The model calculated the concentration of methylmercury for the water column generally agreed with the measured values reported in literature for Aha Reservoir. Combined ArcGIS 9.3 and WASP 7, the spatial and temporal variations of methylmercury concentration were got in Aha Reservoir. The MeHg concentration was different for eight segments and increased for segments $1,4,5,7$ and 8 , decreased for segments 3 and 6 , and changed little for segment 2 from March to August in 2005.
\end{abstract}

Index Terms-Water quality; WASP 7; Mercury module; Methylmercury (MeHg); The Aha Reservoir; Spatio-temporal variation

\section{INTRODUCTION}

Mercury is a very toxic metal. Many studies have been dedicated to mercury cycle in the environment, the physical and biogeochemical transport and transformation of mercury within aquatic systems, and the chemical and biological mechanisms that effect the transformations of mercury in water0[2][3][4][5].

Besides elemental mercury (quicksilver), the major forms of mercury in water are divalent mercury (which is bound to chloride, sulfide, or organic acids) and organic mercury, particularly methylmercury ( $\mathrm{MeHg}$ ). While all mercury species is very toxic, the organic mercury species rather than inorganic mercury can bioaccumulate because it is the only form of mercury that is better retained by organisms at various levels in the aquatic food chain [6]. $\mathrm{MeHg}$ accounts for the majority of the organic mercury specie in freshwater systems. The most toxic form of mercury is $\mathrm{MeHg}$. Even very low concentrations of $\mathrm{MeHg}$ in water, bioaccumulation through food web may cause high levels of mercury contamination in fish from in aquatic systems [7]. Aquatic food consumption is the primary source of $\mathrm{MeHg}$ exposure in humans. The toxic effects of $\mathrm{MeHg}$ are well known. In Japan, many thousands more people were affected and more than 1000 have died due to Minamata Disease which is $\mathrm{MeHg}$ poisoning that occurred in humans who ingested fish contaminated with $\mathrm{MeHg}$ [8][9]. $\mathrm{So}, \mathrm{MeHg}$ is the species of greatest concern for both human health and ecosystems [4][10]. Some country established water quality criteria for $\mathrm{MeHg}$ to protect human health and aquatic life [11].

In this work, the distribution of the $\mathrm{MeHg}$ concentration of Aha Reservoir was studied. Lake Aha, is the drinking water source of Guiyang City, China [12][13][14]. Its water supply capacity is 0.23 million tons per day. In Aha Reservoir, the concentration of $\mathrm{MeHg}$ exceeds the concentration in the other natural lake in the world [14]. From March to August 2005, it was measured and researched the concentration, transportation and fate of mercury species in lake water columns, lake tributaries water, lake sediment profiles and fish from Aha reservoir[12][13][14]. Nonetheless we still have an incomplete understanding of the spatio-temporal distribution of the concentration of $\mathrm{MeHg}$ in Aha Reservoir.

\section{STUDY SITE}

Lake Aha, which is located in the suburbs of Guiyang City, Guizhou Province, China, is a medium-sized artificial reservoir built in 1960. Lake Aha has a surface area of 4.15 $\mathrm{km}^{2}$, a volume of $0.445 \times 10^{9} \mathrm{~m}^{3}$ (a length of $517 \mathrm{~km}$ and a maximum width of $419 \mathrm{~km}$ ), and mean and maximum depth of 13 and $24 \mathrm{~m}$, respectively. Its mean water flux is $1.02 \times 10^{9}$ $\mathrm{m}^{3} \cdot \mathrm{a}^{-1}$, and the residence time of water is $0.44 \mathrm{a}$. It slightly remains thermally stratified in the summer and autumn [14][15].

Supplying water for Lake Aha, the main inflowing rivers are Youyu River, Baiyan River, Sha River, Lannigou River and Caichong River (Fig. 1). The only outflow river is Xiaoche River. Lake Aha was contaminated by the coal mines waste water and domestic sewage. After 1990's, domestic sewage and industrial waste water were the main pollution source in the Aha Reservoir for the mine waste water was controlled. The main pollution comes from the coal mines waste water carried by Youyu River, Baiyan River and Caichong River and the domestic sewage and industrial waste water from Sha River and Lannigou River [12][13][14].

The concentration of different mercury species in the water columns and sediment profile collected from two sampling sites of Aha Lake were investigated in 2005 [12][13][14]. The concentrations of total mercury, $\mathrm{MeHg}$ and reactive mercury are 7.1-47.9 ng/L, 0.16-2.5 ng/L and $0.25-2.43 \mathrm{ng} / \mathrm{L}$ respectively. Discernible seasonal variation of different mercury species were obtained during the sampling periods, with the concentrations in high flow period generally higher than those in low flow period [12][13][14]. However the spatial distribution of different mercuryspecies was not get by two sampling sites. So, in this study, we studied the spatio-temporal distribution of the 
$\mathrm{MeHg}$ concentration for it is the most important form of mercury that accumulates in aquatic food webs.

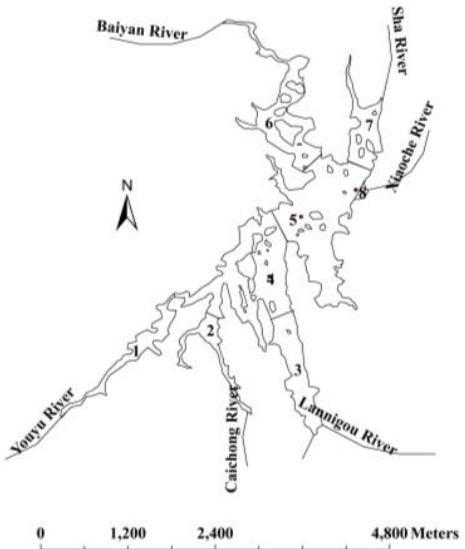

Fig.1 Configuration of mercury model segments with segment number and river in Aha Reservoir

\section{MATERIALS AND METHODS}

In this work, the Water Quality Analysis Simulation Program (WASP 7, USEPA) model was used for simulation of mercury transport and transformation processes in the Aha Reservoir. WASP is applicable to all kinds of aquatic systems. A subset of the WASP7 general toxic chemical module TOXI7 is used by the WASP7 mercury module MERC7 to simulate mercury cycling and transport through a water body. MERC7 simulates three mercury species, elemental mercury $\left(\mathrm{Hg}^{0}\right)$, divalent $\mathrm{Hg}(\mathrm{Hg}(\mathrm{II}))$, and $\mathrm{MeHg}$, as well as one to three solids types (i.e., silt, sand, biotic solids). MERC7 calculates mercury species and solids concentrations in the water column and sediments of each reach throughout the simulation period. With user-specified partition coefficients, $\mathrm{Hg}$ (II) and $\mathrm{MeHg}$ are partitioned to suspended and benthic solids and to dissolved organic carbon (DOC). The model includes several transformation reactions of mercury species that are oxidation of $\mathrm{Hg}^{0}$ in the water column, reduction and methylation of $\mathrm{Hg}$ (II) and demethylation of $\mathrm{MeHg}$ in the water column and sediment layers. A detailed description of WASP 7 and the mercury module model is provided in WASP 6 manual and the overview of the Wasp7 Mercury Module which is available in the Web [16]. Earlier versions of WASP have been used to examine the effects of remedial actions on mercury speciation and transport in a lake system [11]. Carroll et al. (2000) focuses on program modifications that predict bank erosion rates and $\mathrm{Hg}$ bank concentrations related to longitudinal slope by using the US EPA RIVMOD, WASP5 and MERC4 numeric codes [10]. Henry et al. (1995) modified WASP 4 included remineralization to simulate release of $\mathrm{Hg}$ from settling particulates for understanding the fate of $\mathrm{Hg}$ in Onondaga Lake, NY [17]. These studies concluded that the WASP model could accurately simulate $\mathrm{Hg}$ fate for the sites studied under given condition, especially the WASP7 is an enhancement of the original WASP [16].

The targeted lake, Aha Reservoir, was conceptually divided into eight segments $(1,2,3,4,5,6,7,8)$ to represent the water column and the benthic sediment (Fig.1). The environmental conditions, mercury transformation rates and partition coefficient may differ in these eight segments. Available modeling parameters such as mercury concentrations, physicochemical, biological and hydrogeological data were collected from the literature that dealt with Aha Reservoir and the remaining parameters were estimated based on the literature[12][13][14][15]. The geometry information of these segments was obtained from Google Earth by ArcGIS 9.3. The WASP 7.3's Mercury model is used for simulating a 5-month period, from March to August 2005, a period where field measurements are available in the literature [12][13][14]. In this model, WASP 7.3 is set to calculate net flow transport across a segment interface, sediment bed volume statically and modeling time step automatically. The averaged velocity fields obtained were used to simulate transport and dispersion of mercury. Several constants and parameters contained in mercury reaction equations must be specified to implement the WASP7 mercury model. Calibrated constant parameters parameter is provided in table. 1 .

TABLE.1 CALIBRATED CONSTANT PARAMETERS FOR WASP 7 MERCURY MODEL

\begin{tabular}{|c|c|}
\hline \multirow{2}{*}{\multicolumn{2}{|c|}{$\begin{array}{l}\text { Constant Parameter } \\
\text { Elemental Mercury }\end{array}$}} \\
\hline & \\
\hline Partition Coefficient of $\mathrm{Hg} 0$ to Silts and Fines $(\mathrm{L} / \mathrm{kg})$ & 0 \\
\hline Log KDOC Partition Coefficient for $\mathrm{Hg} 0$ (L/kg) & 0 \\
\hline $\begin{array}{l}\text { Reaction Yield Coefficent Elemental to Divalent } \\
\text { Mercury (Mass Basis) }\end{array}$ & 1 \\
\hline $\begin{array}{l}\text { Henry's Law Constant for Elemental Mercury (atm- } \\
\text { m3/mole) }\end{array}$ & 0.0071 \\
\hline \multicolumn{2}{|l|}{ Divalent Mercury } \\
\hline Partition Coefficient of $\mathrm{HgII}$ to Silts and Fines $(\mathrm{L} / \mathrm{kg})$ & 500000 \\
\hline Partition Coefficient of $\mathrm{HgII}$ to Sands ( $\mathrm{L} / \mathrm{kg})$ & 1000 \\
\hline Log DOC Partition Coefficient for HgII & 4.5 \\
\hline $\begin{array}{l}\text { Measured surface photoreduction rate constant for } \mathrm{HgII} \text {, } \\
\text { 1/day }\end{array}$ & 0.01 \\
\hline $\begin{array}{l}\text { Reaction Yield Coef. for photoreduction of divalent } \\
\text { mercury to elemental mercury }\end{array}$ & 1 \\
\hline Quantum Yield for Dissolved Divalent Mercury & 1 \\
\hline Quantum Yield for Sediment-Sorbed Divalent Mercury & 1 \\
\hline $\begin{array}{l}\text { Methylation Rate Multiplier for Dissolved Divalent } \\
\text { Mercury }\end{array}$ & 1 \\
\hline $\begin{array}{l}\text { Methylation Rate Multiplier for Sediment-Sorbed } \\
\text { Divalent Mercury }\end{array}$ & 1 \\
\hline $\begin{array}{l}\text { Reaction Yield Coefficient for Water Column } \\
\text { Methylation (Mass Basis) }\end{array}$ & 1.07 \\
\hline $\begin{array}{l}\text { Reaction Yield Coefficient for Benthic Methylation } \\
\text { (Mass Basis) }\end{array}$ & 1.07 \\
\hline Methyl Mercury & \\
\hline Partition Coefficient of $\mathrm{MeHg}$ to Silts and Fines ( $\mathrm{L} / \mathrm{kg}$ ) & 500000 \\
\hline Partition Coefficient of MeHg to Sands $(\mathrm{L} / \mathrm{kg})$ & 1000 \\
\hline Log DOC Partition Coefficient for $\mathrm{MeHg}$ & 5.5 \\
\hline $\begin{array}{l}\text { Bacterial Demethylation Rate Multiplier for Dissolved } \\
\mathrm{MeHg}\end{array}$ & 1 \\
\hline $\begin{array}{l}\text { Bacterial Demethylation Rate Multiplier for Sediment } \\
\text { Sorbed } \mathrm{MeHg}\end{array}$ & 1 \\
\hline $\begin{array}{l}\text { Yield Coefficient for Bacterial Demethylation of } \mathrm{MeHg} \\
\text { to HgII, g/g }\end{array}$ & 0.93 \\
\hline Surface photo-demethylation rate constant, $1 /$ day & 0.05 \\
\hline $\begin{array}{l}\text { Yield Coefficient for photoreduction of } \mathrm{MeHg} \text { to } \mathrm{Hg} 0 \text {, } \\
\mathrm{g} / \mathrm{g}\end{array}$ & 0.93 \\
\hline Quantum Yield for Dissolved Methlymercury & 1 \\
\hline Quantum Yield for Sediment-Sorbed Methlymercury & 1 \\
\hline
\end{tabular}




\section{RESULTS AND DISCUSSION}

The model was calibrated by adjusting the constants parameters in different segments. Generally, the observations agreed with simulation results for the concentration of $\mathrm{MeHg}$. Only the difference between models and observations in segment 3 is large while those of other segments were small (Fig.2). An acceptable agreement was achieved.

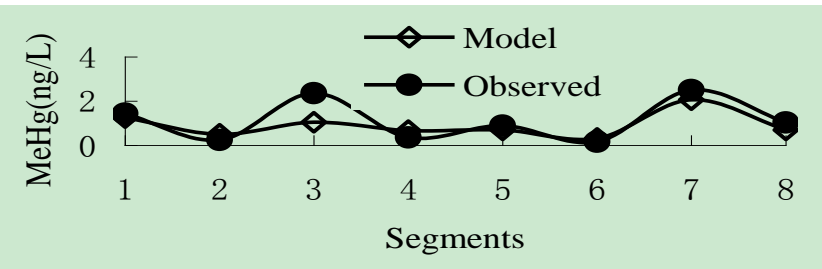

Fig. 2 Validation charts. Observed data (August, 2005) and model results

Coverage of Aha Reservoir and related database was developed using the ArcGIS 9.3 program. The database which has one field, SEGID, is used to align the mercury model predicted results with the correct segments. Then the spatial and temporal variations of the concentration of $\mathrm{MeHg}$ are analyzed.

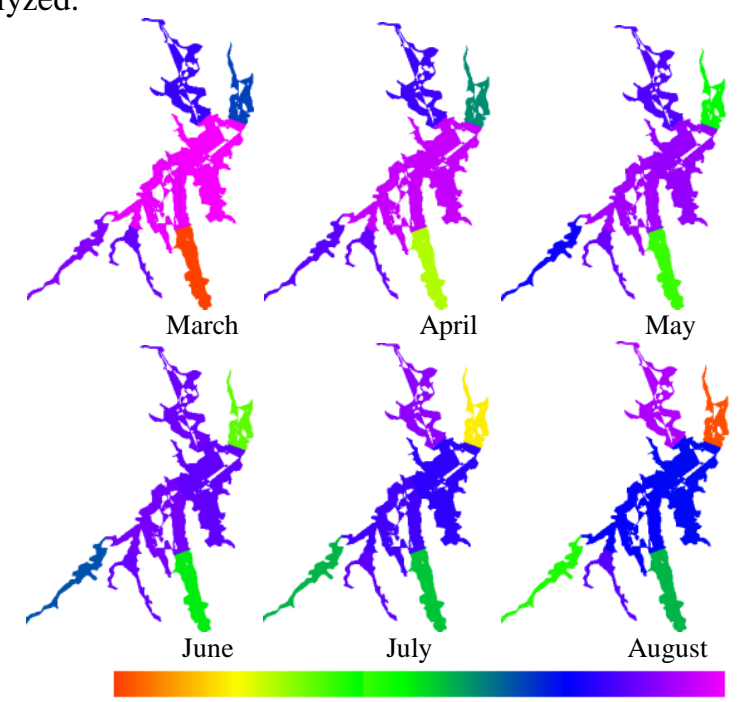

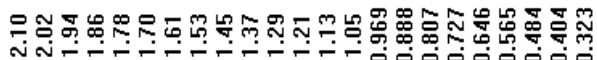

Fig.3 The spatial distribution of simulated concentration of $\mathrm{MeHg}(\mathrm{ng} / \mathrm{L})$ in Aha Reservoir in 2005

The spatial variations of the concentration of $\mathrm{MeHg}$ in Aha Reservoir from March to August in 2005 were observed (Fig.3 and Fig.4). The concentration of MeHg was different in these eight segments from March to August. Except segments 4, 5 and 8 , the difference of other segment was distinct. There was little difference in $\mathrm{MeHg}$ concentrations between segments 4, 5 and 8. In addition, the difference in the concentration of $\mathrm{MeHg}$ between segments 5 and 8 is smaller than that between segments 4 and 5 . That the difference in the $\mathrm{MeHg}$ concentration among segments is obviously can be explained by the inflow. The segment 8 was connected with the only outflow river of Aha Reservoir, Xiaoche River and segment 5 . So it is not affected directly by water quantity and quality of other inflow water and only by segment 5 . This may the reason of the difference of the $\mathrm{MeHg}$ concentration in segments 5 and 8 is the least. In contrast, the segments 4 and 5 were influenced by different inflow rivers with different discharges and loads. This may be lead to the difference of the $\mathrm{MeHg}$ concentration in segments 4 and 5 is bigger than that in segments 5 and 8 .

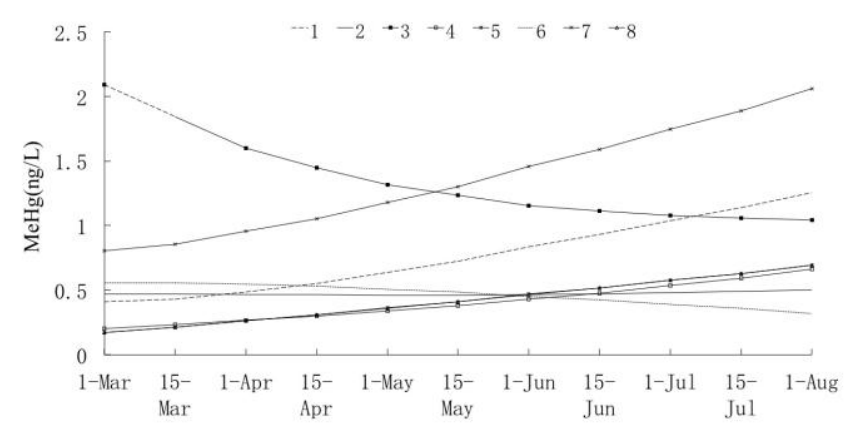

Fig.4 The temporal variation of simulated concentration of $\mathrm{MeHg}(\mathrm{ng} / \mathrm{L})$ in Aha Reservoir from March to August, 2005

Significant temporal variation of the concentration of $\mathrm{MeHg}$ for each segment was observed (Fig. 4). The $\mathrm{MeHg}$ concentration increased for segments $1,4,5,7$ and 8 , changed little for segment 2 and decreased for segments 3 and 6 . The temporal variations of $\mathrm{MeHg}$ concentration in segments 1,4 , 5,7 and 8 agreed well with the previous experimental results [12][13]. MeHg and other mercury species in these segments increased from the low flow period (March) to the high flow period (August) in Aha Reservoir. However, interestingly, for segment 3 and 6 , our simulation result was contrast to the previous experimental results [12][13]. In general, the $\mathrm{MeHg}$ concentration is low in the high flow period for the water dilution. The input river of the lake Aha, Youyu River, Baiyan River and Caichong River all flow through the coal mines areas. The temporal varation of $\mathrm{MeHg}$ concentration in segments 1, 2 and 6 should be similar. Only considered the effect of river inflow, we can not understand the variation.

The observed spatial and temporal variations of the concentration of $\mathrm{MeHg}$ were related to several factors, such as the mercury processes included by WASP and parameters of hydraulic geometry, environment, transport, boundary, transformation and partition. So do that of the Aha Reservoir water body. Among the segments, one factor is different, the $\mathrm{MeHg}$ concentration will differ. In order to better understand the spatio-temporal variation of the $\mathrm{MeHg}$ concentration, further study is needed.

\section{CONCLUSION}

The $\mathrm{MeHg}$ concentrations in the water column were simulated by using WASP. The modelling results consist to the measured mercury concentrations reported in literature in the water compartment of the Aha Reservoir. The spatiotemporal distribution of the concentration of $\mathrm{MeHg}$ in Aha Reservoir was achieved by combining ArcGIS and WASP 7. The MeHg Concentration of the eight segments is different, except those of segments 4,5 and 8 have some similar. In addition, from March to August in 2005, the $\mathrm{MeHg}$ Concentration increased for the segments 1, 4, 5, 7 and 8, decreased for segments 3 and 6 , and changed little for segment 2 . The cause for the spatio-temporal variation of the 
$\mathrm{MeHg}$ concentration is very complex. It is related to all kinds of mercury processes in WASP and other parameters such as hydraulic geometry, transport, boundary, transformation and partition. For analyzing the reason of the variation, further study is needed.

\section{ACKNOWLEDGMENT}

The authors are grateful to Fulong Chen and Qinglong $\mathrm{Fu}$ of Xinjiang Institute of Ecology and Geography, Chinese Academy of Sciences (CAS) for their help in the experiments. The able technical assistance provided by ShuYong Mu (the Director), Li Zhao, Xin Wang, and Qianqian Du of the Center laboratory of Xinjiang Institute of Ecology and Geography, CAS is gratefully acknowledged. Financial assistance from National Natural Science Foundation of China (NSFC) (No. 41101040), "Western Light" Talents Training Program of CAS (XBBS201005, XBBS201010), Knowledge Innovation Program of Chinese Academy of Sciences (KZCX2-YW-335) and Program of 100 Distinguished Young Scientists of the Chinese Academy of Sciences is thankfully acknowledged.

\section{REFERENCES}

[1] C. L. Babiarz, J. P. Hurley, J. M. Benoit, M. M. Shafer, A. W. Andren, and D. A. Webb, "Seasonal influences on partitioning and transport of total and methyl-mercury in rivers from contrasting watersheds," Biogeochemistry, vol. 41, pp. 237257, 1998.

[2] G. A. Gill, and K.W. Bruland, "Mercury speciation in surface freshwater systems in California and other areas," Environmental Science \& Technology, vol. 24, pp. 13921400, 1990.

[3] R. P. Mason, W. F. Fitzgerald, and F. M. Morel, "Biogeochemical cycling of elemental mercury: Anthropogenic influences," Geochimica et Cosmochimica Acta, vol. 58, pp.3191-3198, 1994.

[4] F. M. M. Morel, A. M. L. Kraepiel, and M. Amyot, "The chemical cycle and bioaccumulation of mercury," Annual Review of Ecology and Systematics, vol. 29, pp.543-566,1998.

[5] P. S. Ramlal, C. A. Kelly, J. W. M.Rudd, and A. Furutani, "Sites of methyl-mercury production in remote Canadian Shield lakes," Canadian Journal of Fisheries and Aquatic Sciences, vol. 50, pp. 972-979, 1993.

[6] E. J. Zillioux, D. B. Porcella, and J. M. Benoit, "Mercury cycling and effects in freshwater wetland ecosystems," Environmental Toxicology and Chemistry, vol. 12, pp.22452264, 1993
[7] Q. Wang, D. Kim, D D. Dionysiou, G. A. Sorial, and D. Timberlake, "Sources and remediation for mercury contamination in aquatic systems-a literature review," Environmental Pollution, vol. 131, pp.323-336, 2004.

[8] M. Harada, "Minamata disease - methylmercury poisoning in Japan caused by environmental pollution," Critical Reviews in Toxicology, vol. 25, pp. 1-24. 1995.

[9] Kudo, and S. Miyahara, "A case-history-Minamata mercury pollution in Japan-from loss of human lives to decontamination," Water Science and Technology, vol. 23, pp. 283, 1991.

[10] R. W. H. Carroll, J. J. Warwick, K. J. Heim, J. C. Bonzongo, J. R. Miller, and W. B. Lyons, "Simulation of mercury transport and fate in the Carson River, Nevada," Ecological Modelling, vol.125, pp. $255-278,2000$.

[11] D. Kim, Q. Wang, G. A. Sorial, D. D. Dionysiou, and D. Timberlake, "A model approach for evaluating effects of remedial actions on mercury speciation and transport in a lake system," Science of the Total Environment, vol. 327, pp. 1-15, 2004.

[12] W. Bai, X. Feng, X. Fu, T. He, and G. Qiu, "The concentration and distribution of different mercury species in the water columns and sediment of Aha Lake," Chinese Journal of Geochemistry, vol. 25, pp. 154-154, 2006.

[13] W. Bai, X. Feng, Z. Jin, L. Sun, and H. Yan, "The influence of rivers on the transport and fate of mercury species in the Aha Reservoir," Acta Mineralogica Sinica vol. 27, pp. 218-224, 2007. (in Chinese with English abstract and title)

[14] W. Bai,.The primary study on the distributions and transformations of the different species Mercury in Aha Reservoir. A dissertation submitted to graduate university of chinese academy of sciences of the degree of master. In the Graduated University of Chinese Academy of Sciences, 2006.

[15] G. Wan, R. Huang, Y. Pu, and X. Wan, "Screening Effect of the Diffusive Boundary Layer in Sediments of Lake Aha in the Suburbs of Guiyang City, Guizhou Province," Chinese Journal of Geochemistry, vol. 16, pp. 347-352, 1997.

[16] T. A. Wool, R. B. Ambrose, J. L. Martin, and E. A. Comer, "Water quality analysis simulation program (WASP) version 6.0 draft: user's manual. available from: http://www.epa.gov/athens/wwqtsc/html/wasp.html, 1996.

[17] E. A. Henry, L. J. Dodge-Murphy, G. N. Bigham, and S. M. Klein, "Modeling the transport and fate of mercury in an urban lake (Onondaga Lake, NY) ," Water, Air and Soil Pollution, vol. 27, pp. 80:489-498, 1995 . 